\title{
Towards a dedicated impact portal to bridge the gap between the impact and climate communities : Lessons from use cases
}

\author{
Céline Déandreis • Christian Pagé • Pascale Braconnot • \\ Lars Bärring • Edoardo Bucchignani • \\ Wim Som de Cerff • Ronald Hutjes • Sylvie Joussaume • \\ Constantin Mares • Serge Planton • Maarten Plieger
}

Received: 22 April 2013 / Accepted: 20 April 2014 / Published online: 27 June 2014

C The Author(s) 2014. This article is published with open access at Springerlink.com

\begin{abstract}
Future climate evolution is of primary importance for the societal, economical, political orientations and decision-making. It explains the increasing use of climate projections as input for quantitative impact studies, assessing vulnerability and defining adaptation strategies in different sectors. Here we analyse 17 national and representative use cases so as to identify the diversity of the demand for climate information depending on user profiles as well as the best practices, methods and tools that are needed to answer the different requests. A particular emphasis is put on
\end{abstract}

Electronic supplementary material The online version of this article (doi:10.1007/s10584-014-1139-7)

contains supplementary material, which is available to authorized users.

C. Déandreis

Institut Pierre SImon Laplace (IPSL), Paris, France

P. Braconnot $(\bowtie)$

Laboratoire des Sciences du Climat et de l'Environnement, CEA-CNRS-UVSQ, Gif-sur-Yvette, 91191 Paris, France

e-mail: pbraconnot@1sce.ipsl.fr

C. Pagé

URA CERFACS/CNRS No1875, SUC au CERFACS, 1875 Toulouse, France

L. Bärring

Rossby Centre, Swedish Meteorological Hydrological Institute (SMHI), Norrköping, Sweden

E. Bucchignani

Euromediterranean Center for Climate Change, Central Maine Community College (CMCC),

Lecce 73100 , Italy

W. S. de Cerff • M. Plieger

Royal Netherlands Meteorological Institute (KNMI), De Bilt, The Netherlands

R. Hutjes

Wageningen University, Wageningen, The Netherlands

S. Joussaume

Institut Pierre SImon Laplace (IPSL)/LSCE, Gif-sur-Yvette, Paris 91191, France 
the workflow that allows to translate climate data into suitable impact data, the way to deal with the different sources of uncertainty and to provide a suited product to users. We identified three complementary tools to close the gap between climate scientists and user needs: an efficient interface between users and providers; an optimized methodology to handle user requests and a portal to facilitate access to data and elaborated products. We detail in the paper how these three tools can limit the intervention of experts, educate users, and lead to the production of useful information. This work provides the basis on which the ENES (European Network for Earth System Modelling) Portal Interface for the Climate Impact Communities is built.

\section{Introduction}

Climate change adaptation is becoming a high priority as shown by the positioning of the political institutions and the increasing number of economical cost studies (IPCC 2007; Hope 2009; National Round Table on the Environment and the Economy, 2011). Integrating such relatively new issues into a complex framework of already existing policy, planning and management processes is challenging and has led to the need to develop "Climate Services" (Global Framework for Climate Services 2011). Future adaptation strategies must be defined with strong scientific bases. It requires compilation of scientific, technical and operational knowledge and know-how through multidisciplinary teams and international coordination.

Climate researchers that are assailed by more and more requests on this subject will not be able to respond to all individual users. The last 10 years have shown a huge increase of the number of data demands from the impact communities, end-users in different economic sectors as well as decision makers for outputs of climate projections or climate diagnoses. The results of global climate models (GCM), such as the ones performed at the international level as part of the Coupled Modelling Intercomparison Project (CMIP) (Meehl et al. 2000, Taylor et al. 2012) represent the scientific ground that serves as a basis for preparing adaptation. Coordinated climate projections have also been run at regional and local scales (ENSEMBLES for Europe, http://www.ensembles-eu.org/ - NARCCAP for North America, http://www.narccap.ucar.edu/ and now CORDEX at the international level, Jones et al. 2011). They are used for studies that consider specific features that are not well represented in global climate simulations, e.g. climate extremes. Finding the way in the large number of datasets and approaches is difficult especially for users without climate expertise. Even though most of the data are easily available through specialised, often project-based databases their use can be misleading without enough background information. Climate simulations suffer from biases that need to be accounted for in order to properly assess vulnerability and opportunity associated with climate change. The propagation of uncertainties along the chain of models and analyses is a matter of concern and needs to be considered and discussed. The ENSEMBLES project proposed methodologies and the use of ensemble simulations to address some of these questions (ENSEMBLES 2009). But further guidance and outreach must be provided for non-expert users.

In this context there is an urgent need to develop and put into place services to guide the users and to promote the best practices to use climate model outputs in impact and adaptation studies. This requires analysing and understanding the user demand and the implication of

C. Mares

National Institute of Hydrology and Water Management (INHGA), Bucuresti, Romania

S. Planton

CNRM - GMGEC, Météo-France, Toulouse, France 
climate scientist to define how the user needs can be fulfilled. This ambitious task has been undertaken as part of the EU-funded IS-ENES infrastructure project (https://is.enes.org). ISENES combines expertise in Earth system modelling, in computational science, and in studies of climate change impacts. A prototype web service interface is under development to bridge the gap between climate research and modelling communities, the climate impact communities, and decision makers for developing adaptation and mitigation policies.

For that purpose, 17 national and representative "use cases for climate data" have been selected. They have been gathered from the experiences of eight research institutes (CERFACS, CMCC, INHGA, IPSL, KNMI, Météo-France, SMHI, WUR) in five European countries (France, Italy, Netherlands, Romania, Sweden). The use cases describe the total workflow from the definition of the request to the delivery of final products giving an overview of practices in these countries. Here we present the lessons learned from the comparison of the cases focusing on scientific questions and technical procedures. The three first sections of this paper describe the use cases and user needs, the processing steps needed to transform a climate date into a suited product, and the methods to deal with uncertainties. Then, we present how the features highlighted by the use cases can serve to set up tools to better interact with users. In the concluding remarks, we propose some recommendations.

\section{Characterizing the user needs from a representative set of use cases}

Use cases are typical examples of studies using outputs of climate projection performed with GCM or regional climate models that have been developed to address impact or vulnerability issues. The 17 IS-ENES use cases (Table 1) were documented using fact sheets that describe the workflow and the interactions between users and climate scientists in a standard way. Although the number of use cases is limited, their diversity in terms of sectors, objectives, user types, areas and periods of interest provide a comprehensive overview.

These use cases address a wide range of questions related to impact and vulnerability, decisionmaking, adaptation strategies or mitigation (Table 1). Hydrology (28\%) and ecology (24\%) are the most frequent sectors in our sample, probably representing the current status as shown by the wealth literature on these particular topics. Hydrological cases deal with the probability of floods and droughts in the future (Netherlands and Loire basin) or the evolution of European river features. Ecologists are interested by the viability of different species in some ecosystems such as freshwater fishes in the French Adour River. Agriculture (12\%), land use (6\%), forestry (6\%) and geotechnics (12\%) also appear several times with interest for the evolution of crop yields in West Africa, France and Europe; the impact of agriculture on land use and greenhouse gases budget; the optimisation of forestry production in Sweden, changed risk of outbreaks of pests and pathogens, plant breeding; management practices and the monitoring of landslides phenomena. These sectors are very sensitive to meteorological factors and decision-makers are already convinced that climate change effects need to be accounted for in their planning (IPCC 2007; European Commission 2009; UNECE 2009; FAO 2007). On the contrary, uncertainties about distribution and timing of impacts at the local level; technological capacity to adapt to more gradual changes; economical resources to recover from strongest impacts, difficulty to estimate costs (benefits) of climate impacts tend to delay societal awareness (IPCC 2007; Wright and Erickson 2003). Only one case deals with industrial sector and the vulnerability of heating networks. One use case aims also to provide a way for users to produce themselves their own climate data.

For most of the use cases in table 1 the work included first an analysis of vulnerability using present and past climate data from observations or model outputs, and a projection to future climate conditions, using output from climate projection under specific socio-economic scenarios. 


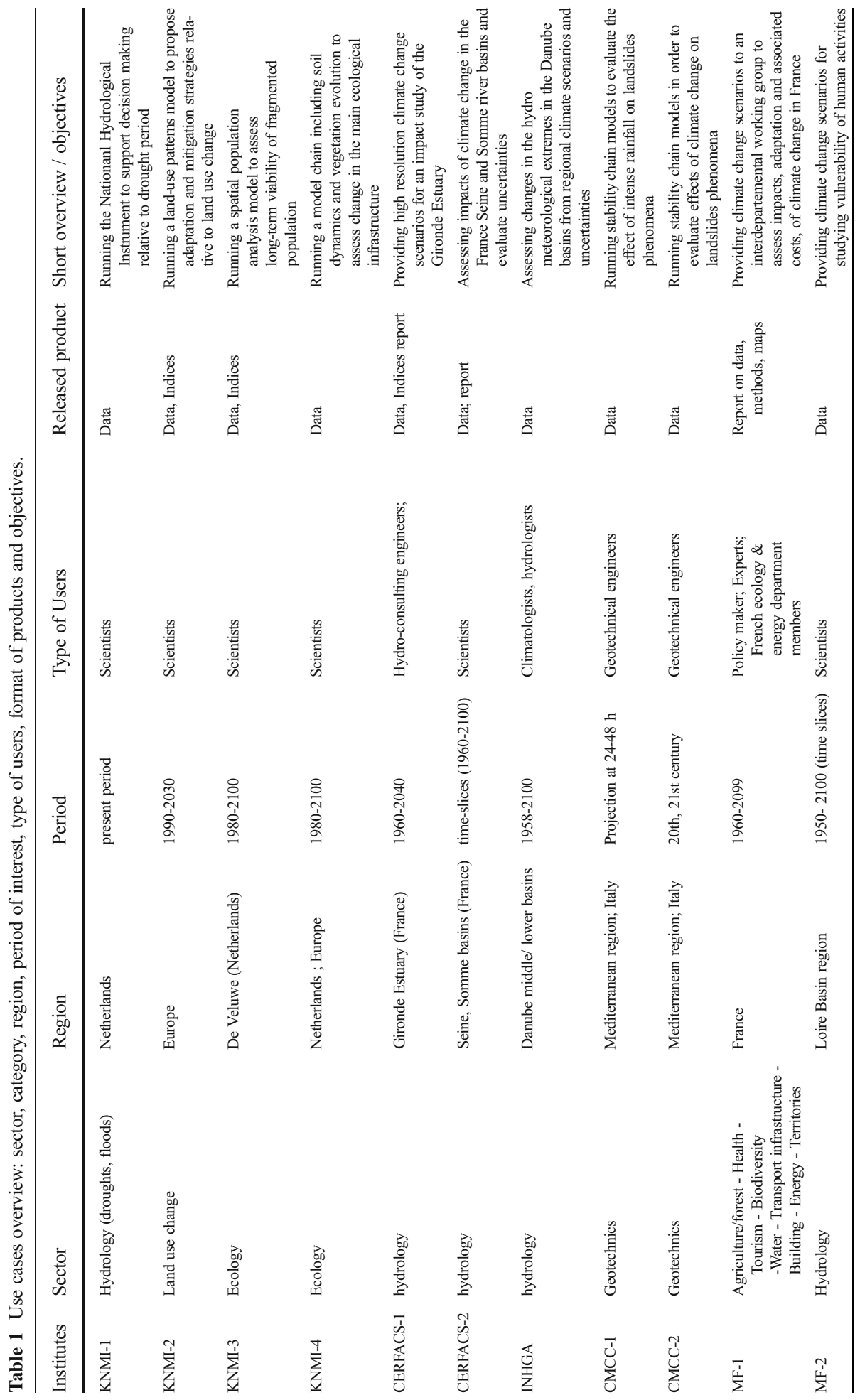




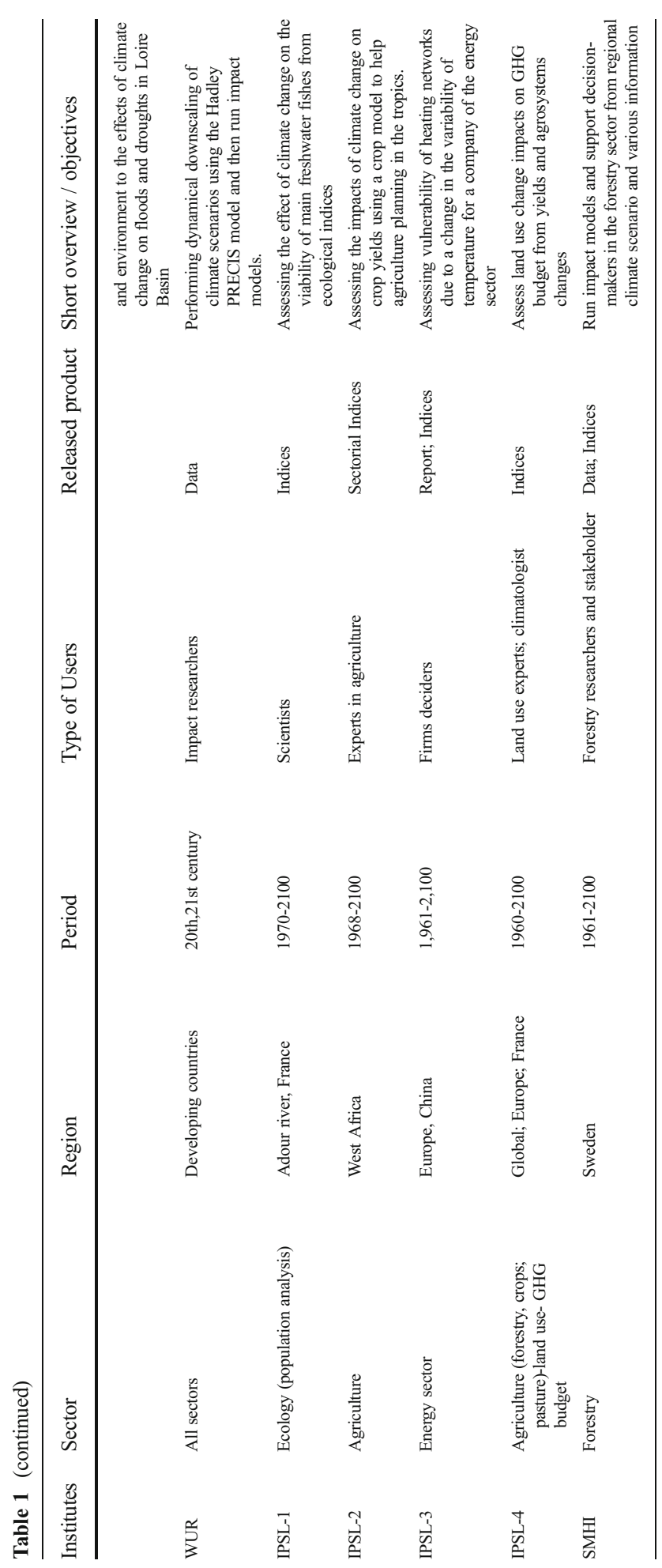


The geographical domains covered by the use cases extend from very local zones like sites with specific ecological properties, rivers and cities (region of De Veluwe in Netherland in KNMI-3 use case) to very large regions like continents (Europe and Mediterranean regions in KNMI-2, CMCC-2 and IPSL-4 cases). Several requests refer to European rivers (Danube, Somme, Seine, Loire, Adour, Gironde) and countries (Netherland, Sweden, Italy and France). Interest is also for non-European areas like developing countries, e.g. Bolivia, China or global scale. This analysis reveals thus that the most frequent requests $(46 \%)$ are for regional data $(7-50 \mathrm{~km})$. Global data $(100-300 \mathrm{~km})$ present also a large score $(42 \%)$ as regional data is not systematically available in some regions. Requests for local data $(<1 \mathrm{~km})$ are still minor $(12 \%)$.

Most of these cases require daily atmospheric data (58\%), followed by "sub-daily" data (29\%). Monthly, yearly and decadal data are not often used in our cases that mainly consider meteorological extremes or use the atmospheric data as input of impact models. The most classical variables used in these studies are surface $(2 \mathrm{~m})$ air temperature, precipitation, and surface $(10 \mathrm{~m})$ wind, but other variables such as geopotential and surface humidity are also considered (see appendix). These variables are in general translated into indices (number of hot days, longest dry-period...) to characterize the intensity, magnitude, duration and spatial extent of meteorological or climate events of interest. As an example, the Palmer Drought Severity Index (Palmer 1965) based on temperature and precipitation is used to characterize the hydrological features of the Danube Basin (INHGA). Dedicated indices need also to be developed to better match with the definition of the vulnerability. The index based on the diurnal temperature range to represent the vulnerability of heating networks to temperature variations (IPSL-3) fits into this category.

The format in which information is delivered has been adapted to the level of expertise of users. Three types of users can be distinguished based on their understanding of climate issue and on their ability to treat the information. "Informed users" have acquired skills to use, analyse and interpret climate information. They are able to produce their own products from raw numerical data. Impact researchers of IS-ENES cases but also climate engineers or consultant can be placed in this category. "Intermediary users" are not able to process raw climate data by themselves and ask for pre-processed data and elaborated products like maps plots or statistics to elaborate their decision. Industrial managers of the IPSL-3 use case stand in this category. "Inexperienced users" have no climate skills and need to be guided throughout the process from the specification to the interpretation of the products. Any users (decision makers, managers, scientists, engineers of any sector) that faced climate issue for a first time are in this category.

An illustration of different formats is given in Fig. 1 for the IPSL-3 use case that addressed the vulnerability of heating network for the energy sector. A specific index based on the diurnal temperature range $\left(D T R=T_{\max }-T_{\min }\right.$ has been co-developed with the stakeholder. Informed users would compute the index by themselves from raw climate data (DTR, $\mathrm{T}_{\max }$ and $\mathrm{T}_{\min }$ ) and would make sensitivity for several vulnerability thresholds to assess climate risk. Large volume of raw data (daily maximum and minimum temperature over the entire period of interest) has to be processed in that particular case. Intermediary users would directly retrieve the index in order to reduce data processing time and data storage and will more probably ask for statistics that offer "concise information", plots that display directly trends and threshold values or maps that allow rapid comparisons of the expected changes in different regions (Fig. 1). Inexperienced users will need a customised support to define their vulnerability sources, determined products suited to their case and interpret results. All these possibilities should be considered when interacting with users. 


\section{a) Data File}

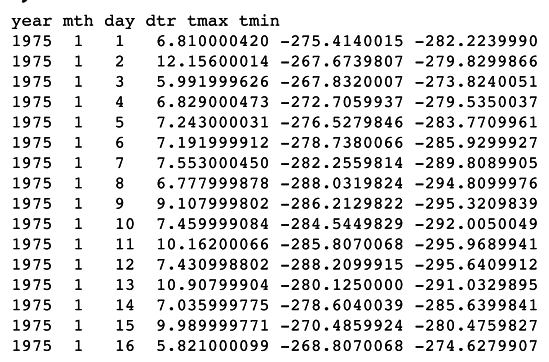

\section{c) Plot}

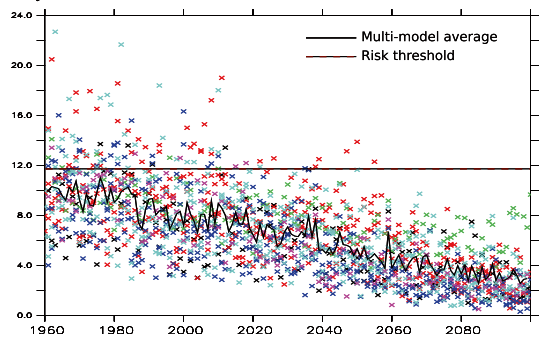

\section{b) Statistics}

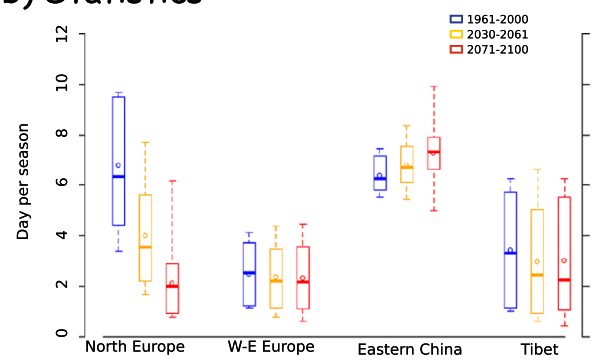

d) Map

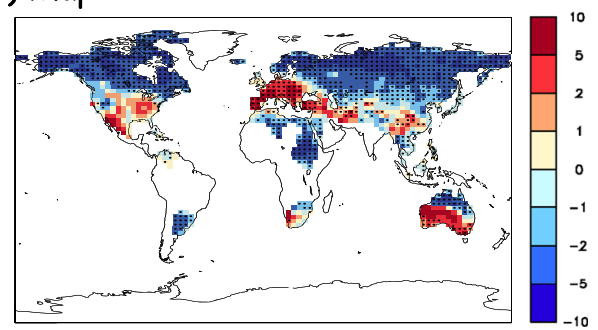

Figure 1 Different products for different users: (a) raw data in different format; (b) statistic of the diurnal temperature range index; (c) plot of the trends of the index in the North of Europe compared to a threshold value (red dashed line); (d) map of the indiex anomaly computed for 2071-2100 period compared to 1971-2000. Illustration from the IPSL-3 use case.

\section{Understanding the different steps to produce relevant information}

The IS-ENES collection of use cases also allows us to compare methods and practices that are used to transform climate model outputs into climate information that is relevant for users. In most cases this is not straightforward. The data processing depend strongly on formats of final products (raw data versus value-added products), data types (parameters, resolution, dataset), and quality requirements (including uncertainties treatment).

\subsection{Selecting spatio-temporal resolutions and datasets}

Making good choice in term of resolution is tough. Users tend to request very fine spatial and temporal resolution as they don't necessarily understand limitation of climate modelling. For landslide phenomena (Table 1), the forecast is needed at100 m resolution. Studying hydrological issue like flood requires sub-daily data. However the benefit of high resolution is not always straightforward (Mearns et al. 2003), and the number of high-resolution datasets are often smaller than those at lower resolutions, limiting uncertainties assessment. The value added of high resolution should be questioned to decide if high resolution is really essential to address the demand and if the available datasets are reliable. However, the use of impact models imposes a constraint on the frequency of meteorological data use as input. For hydrology, three hours data needed to represent the daily cycle of precipitation. They can only be provided with caution. Climate model have systematic biases in reproducing properly the diurnal cycle of precipitation (Dai 2006) and assumptions are necessarily made to develop statistical methods (like weather generator). Though, downscaling can improve the representation of short temporal variability, confidence in such data is still weak (Maraun et al. 2010). 
In the use cases, raw data come mainly from international databases. These databases are first put into place for research studies and provide huge amount of data with specialised formats. This is the case for the CMIP databases (https://esg.llnl.gov:8443/) that includes a large number of models, scenarios and ensemble members at global scale, or of the new CORDEX database (Jones et al. 2011). For more local data, the sources are more diverse and more often include only a limited number of results from socio-economic scenarios and models. Some databases are also dedicated to indices (STARDEX: http://www.cru.uea.ac.uk/projects/stardex/ or ECA\&D: http://eca.knmi.nl). Observation and reanalysis mainly come from meteorological centre databases that are not free in many countries. Most of these databases are only exploitable by expert users because the description of the content, data formats, presentation and ergonomics are highly specialised. Web services are emerging that attempt to guide the users and distribute raw data or more elaborated indices (i.e. Lémond et al. 2011).

\subsection{Data Processing, methods and tools}

Crossing the use cases allowed to establish a comprehensive list of processing steps needed to transform raw model output into customized products (see appendix for details). Processing raw data relies on complex methods and highly specialised tools. Data extraction, grid interpolation, subsetting and reformatting are performed to reduce the overall data volume, prepare and standardize datasets. Simple (min, max, average, sum, etc.) and more complex statistical transformations are used to analyse biases, correct data, compute indices and assess uncertainties. Downscaling is another key step in the process used to increase the spatial and/or temporal resolutions that are essential to carry out some impacts. Data visualisation is used to illustrate and check results.

For example, the geographic projections used in the IS-ENES use cases are regular or irregular latitude/longitude coordinates on the sphere or on various ellipsoids, e.g. Lambert conformal conic projection, or the Dutch national grid. For each case, an adequate method has been chosen by climatologists following scientific and technical constraints. For example, in the KNMI-2 use case, the bilinear interpolation has been chosen rather than the nearest neighbour one because the land-use impact model is very sensitive to discontinuous transitions. In the INHGA case, the spline interpolation is well adapted to treat irregular time scale and the hydro-meteorological extremes in the Danube Basin.

Another example of the multitude of tools is illustrated for "downscaling". In our 17 use cases, five regional climate models are involved as well as statistical methods based on weather classification methods; stochastic tools and on the less usual classification and regression tree method (details in Appendix). In some cases, both dynamical and statistical tools have been combined. For example in the Swedish forestry use case, an ensemble of GCM scenarios is downscaled using the regional climate model RCA3. The RCM output is then further downscaled and calibrated using either a simplistic quantile-quantile approach or a more sophisticated statistical procedure taking seasonal variations in weather patterns into account (Yang et al. 2010).

The different technical steps needed to transform data and deliver final product to users may vary from one case to the other. In the MF-1 use case (Table 1), computing indices of climate impacts and costs for several activity sectors in France implies to get data at a appropriate resolution over France, select observation and regrid all data (model and reanalysis) to perform correction, compute standard indices and assess uncertainties for two socio-economic scenarios and two models. The final product has been customised for non-expert users via statistical analyses and graphical visualisations. On the other hand, the CMCC-2 use case aims to provide data to expert users to feed a landslide phenomena impact model at a very fine scale 
$(100 \mathrm{~m})$. The needed atmospheric variables were downscaled using a combination of dynamical regional and statistical local downscaling.

As shown by these two examples, the fine processing choices are partly constrained by technical and quality requirements. (There is a need to limit the load of data to deliver taking into account users capacity to process, analyse and store data. Similarly the processing time should match with users specifications and the timing of decision-making; while keeping the objective to provide reliable products). Knowledge of the methods, their limits and strengths is essential to manage data processing. Note that expert considerations should not override the demand and specifications of users.

\section{Uncertainties}

Dealing with the different sources of uncertainty is a major difficulty of impact studies. Uncertainties are in general considered responsible for decreasing their quality (Carter et al. 1999). Sources of uncertainties are indeed numerous, but all of them do not necessarily affect the robustness of the result. Assessing the different sources of uncertainty is needed to communicate to users the degree of certainty in the results (Mastrandrea et al. 2010). It will influence the way users will use data for decision making, and should ideally be analysed considering specificities of each activity.

From the analysis of the different IS-ENES use cases it sounds important not to mix up all the uncertainties, but to consider them as different categories. We therefore classified them in table 2 as inherent uncertainties, model uncertainties and method limitations. For each of these categories, we highlight different types of uncertainties that have been mentioned in the use cases and indicate both if a method has been developed to deal with them and if actions have been considered to quantify them or assess their impact on the final result.

Some of these uncertainties are inherent to climate studies. They concern the limited understanding of climate system or its natural variability that covers a wide range of timescales from daily to multi decadal ones or more and results from internal noise or from the natural forcing (solar constant or volcanic eruptions). For future projections, climate change uncertainties concern the unpredictable socio-economical behaviour. These projections are only to be considered as possible trajectories that help to drive the discussion and decision, without forgetting that specific hypotheses on the level of greenhouses gases, aerosols emissions or land use have been made to conduct them. In some cases, these hypotheses affect the choice of simulations that should be considered to answer specific user needs. Imperfections of models are other sources. Global and regional models are limited due to the representation of sub-scale processes (parameterisation), missing processes, tuning and initialisation issues (Hourdin et al. 2013). In addition, statistical methods, especially downscaling, hourly and grid interpolations generate additional errors that may also affect the results.

Time horizon is very important when dealing with these uncertainties. The relative importance of the three major sources of uncertainties (natural variability, scenario and model) moves with time horizon (Hawkins and Sutton 2009). Because of the strong impact of natural variability in short-time projection, the shortest is the projection time, the poorest is the signal/ noise ratio. It explains why despite many user requests for short-time projections (2020), most use cases have been performed for the end or the middle of the century $(2100 ; 2050)$ to provide a better understanding of the impact of man induced climate change. In opposition to natural variability, the uncertainties due to socio-economic scenario increase largely at the end of the century. For this time horizon the comparison between them clearly allows to differentiate the role of socio-economic factors on impacts. Model uncertainties are quite high throughout time and should be assessed whatever the time horizon. 
Table 2 shows that methods were used to quantify uncertainties by assessing a range of values via multi-scenario, multi-model, multi-ensemble and multi-downscaling analyses. They have been performed considering each model with equal weight (most frequent) which is in line with the practical implications of a weighting exercise for RCM evaluation (Kjellström and Giorgi 2010); considering only a subset of models or using entropy method (only one case). Best practices for standardized multi-projections assessment are discussed in Knutti et al. (2010).

In most cases, systematic models biases resulting in a systematic shift of the values, such as a mean cold bias for temperature, or a shift in the shape of the distribution of the different values, do not allow to properly assess thresholds or the expected magnitude of future climatic variables or indices of importance to assess future risk. Data correction is used to reduce the impact of such biases on the result. Tailored versions of the percentiles matching transformation (Panofsky and Brier 1968) are the most common methods used in our use cases (see Appendix for details). Comparison of different methods/tools is also a way to deal with statistical or analytical uncertainties. Depending on the case, only the results of the best method or the range of values from all the methods was considered in the final result.

Quantifying separately each source of uncertainties is a key aspect of the whole expertise but is out of interest for most final users (except expert users). Technical details are not necessary and may lead to erroneous understanding and misleading communication with the user. A summary of this information and how it affects the study for the different periods and regions of interest should however be mandatory. Expert judgments naturally enter into play in this last step.

\section{Closing the gaps between climate scientists and user needs}

Producing relevant information relies on an efficient interface between users and experts. Interaction is needed throughout the process from the validation of the user's request to the delivering of final products. In the use cases, interaction has been managed directly by scientists. Part of this work should be achieved by practitioners that will facilitate translation, collaboration, and mediation (Cash 2006).

The use cases highlight the knowledge needed to treat raw climate data, data format, methods of processing and analyses of the results. Most of the subjects require information at the forefront of basic research. Effort to improve the transfer of knowledge and help users to better formulate their requests already started with the edition of several guidelines (IPCC-TGCIAccpo 1999; Mastrandea et al., 2010; Knutti et al. 2010). A consistent language has been developed for the treatment of uncertainties (Moss et al. 2000; Patt and Schrag 2003). Next step would be to simplify this information and make it easily available.

All the steps described in the different use cases are part of climate services. The analysis of their differences, their similarities and their limits, allow us to build a generic workflow (Fig. 2) that should foster the co-production of information and better interactions between the providers of climate information and users. It is a framework that includes seven steps so as to reflect the whole chain of values and actions needed to take into account user specifications, to use at best scientific expertises and to deliver useful products as well as suited guidances. Quality assessment (step 5) is at the heart of the workflow since any data should be delivered with information on their reliability. It stresses that the datasets and methods selected during the processing choices step should be revised if data quality is not sufficient. In some cases a reformulation of the initial request is necessary (step 1). At each step, user/expert interaction (via direct communication, report, guidance) allows to improve user's awareness, satisfaction 


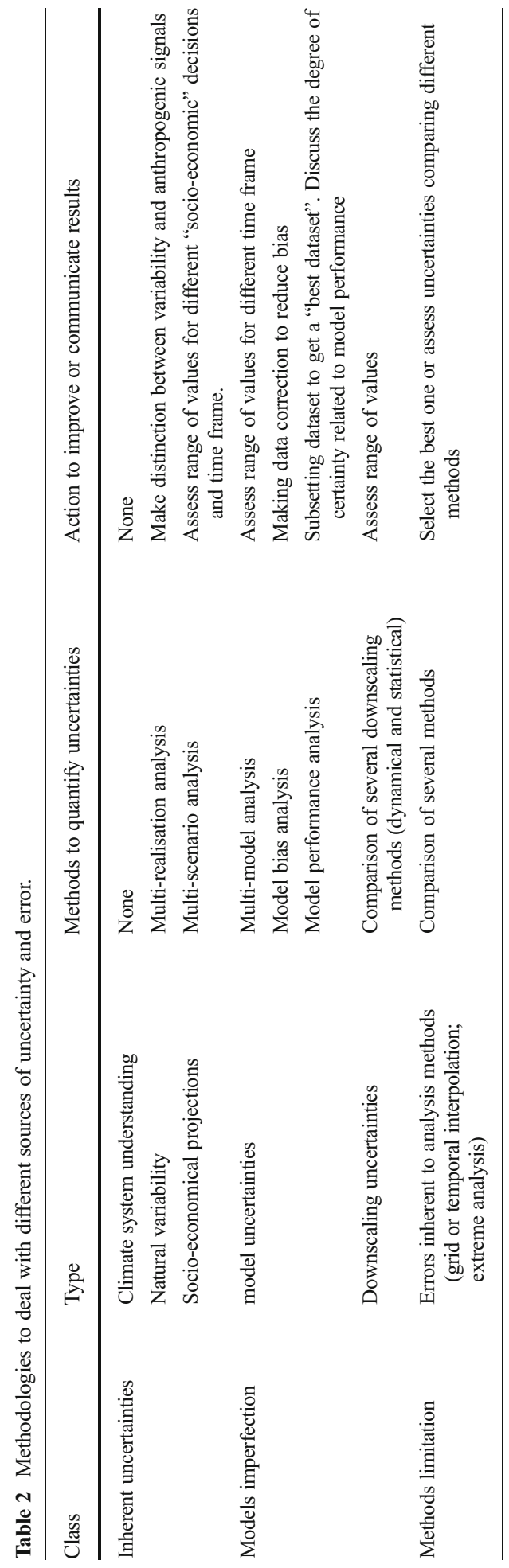




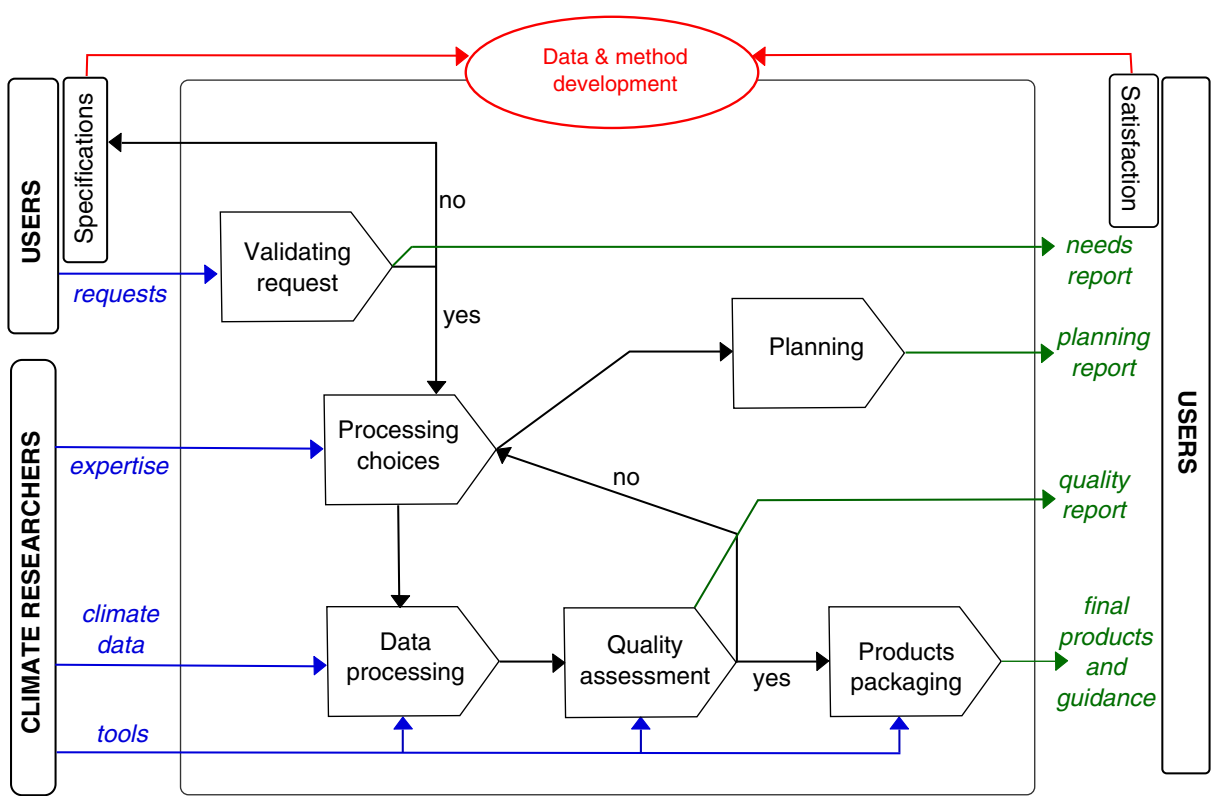

Figure 2 Generic workflow for the production and release of climate information for impact and decisionmaking communities

and confidence in the results. Several reports should be delivered. They should cover how the specification of users have been translated regarding scientific possibilities (including information about data resolutions and format), planning reports on the different steps and decisions for data processing, and a quality report presenting the level of confidence in products and a summary about methodologies. Guidance should also be provided to promote the best use of the final products.

Finally bridging the gap between climate scientists and users requires facilitating data access. It can be achieved by setting up a dedicated e-portal that includes technical and support services. In this line our workflow is used to showcase the different use cases on IS-ENES portal, so that they can be used as example and directly reused when suited in other studies. It come in complement to technical services that are put into place to propose a data access via a user-friendly interface presenting the different variables, sets of simulations, models, scenarios. We recommend that data with low confidence like those at very high resolution $(100 \mathrm{~m}$ or subdaily data) should not be proposed, except if they become part of a particular user service. The use cases showed that each study needs specific choices, methods and sequence of steps. To help users in their attempt without intervention of experts, services should be proposed for each step of the generic workflow. At least, 3 kinds of sequences should be illustrated, documented, and achievable via the portal: the first one consists in retrieving large data series for running impact models, the second one will propose a sequence of steps to correct data and compute indices or other statistics, the last sequence relates to products visualisation. Support services should ensure that data are used in a proper way and that the final products cannot be misinterpreted. In addition, a hotline should be available to provide further information, specific data and methods, but also to guide users when their requests need additional expertise. Such e-portal structure should remain flexible. Climate science progresses rapidly, and new data, methods and tools have to be providing with almost no delay to users, allowing to answer more requests and to increase efficiency and capability of the portal. 


\section{Concluding remarks}

Users need tailored information that should be co-produced by users and climate experts. It requires better interaction, understanding and communication between these two communities.

Climate scientist should better understand user needs, which also requires that users should be educated to better formulate their requests regarding availability and reliability of data and tools. This implies that beyond general information on climate physics and modelling, they should get synthetic information about the different types of products and their formats, the different sources of uncertainties and how they affect the final products.

The work undertaken throughout the processing chain from climate model output to delivery of climate information is time-consuming and not well understood neither by the user communities, nor by the research communities, mainly because it is a fast emerging topic. Part of this activity should become operational. Web services via a dedicated e-portal can support part of this task. It can facilitate data access. It is also an intermediary to spread information about climate change for many users. Finally, it can help users to understand processing methodology via practical examples and reproduce it for similar cases without the intervention of experts. From the analyses of 17 use cases documented by the European partners of the IS-ENES infrastructure project, we identify that event if impact studies are very diverse it is possible to propose a generic workflow to standardize methodologies and interactions between the provider of climate information and users. We also propose that this workflow help to put into place climate services through dedicated e-portal. Such a portal will not allow answering all types of requests. Indeed answering user request requires to understand users culture and in lots of cases to reformulate the request. Climate scientists should be supported in this task by practitioners that own knowledge of climate data and tools as well as knowledge of users and their needs.

The development of common tools and practices for climate change impact studies is a fast evolving subject that will benefit from interaction between initiatives from other national, European and international projects. IS-ENES is the European contribution to this global effort.

Acknowledgement This work is supported by the European FP7 project IS-ENES, grant number 228203 and the French SECIF project (ANR CEP\&S 2010). The Swedish case studies are based on research carried out within the Swedish Mistra-SWECIA programme funded by Mistra (the Foundation for Strategic Environmental Research). The IPSL-4 use case is based on results of the INVULNERABLe Project (http://www.iddri.org/Iddri/ Fondation/INVULNERABLe-Project).

Open Access This article is distributed under the terms of the Creative Commons Attribution License which permits any use, distribution, and reproduction in any medium, provided the original author(s) and the source are credited.

\section{References}

Canada. National Round Table on the Environment and the Economy (2011) Paying the Price: The Economic Impacts of Climate Change for Canada, Climate Prosperity; Report 04, 168pp

Carter TR, Hulme M, Viner D (1999) Representing uncertainty in climate change scenarios and impact studies. Proceedings, ECLAT-2 Helsinki Workshop, Finland, 128 pp

Cash DW (2006) Countering the Loading-Dock Approach to Linking Science and Decision Making: Comparative Analysis of El Nino/Southern Oscillation (ENSO) Forecasting Systems. Science Technology \& Human Values 31(4):465-494

Dai A (2006) Precipitation characteristics in eighteen coupled climate models. J Climate 19:4605-4630 
ENSEMBLES (2009) Climate change and its impacts: summary of research and results from the ENSEMBLES project. Van der Linden P., Mitchell JFB (eds), Met Office Hadley Centre, Exeter, 160 pp

European Commission (2009) River basin management in a climate change. Common implementation strategy for the water framework directive (2000/60/EC) - Guidance document No. 24, 134 pp. Available at http://ec. europa.eu/environment/water/index_en.htm

FAO (2007) Adaptation to climate change in agriculture, forestry and fisheries: Perspective, framework and priorities. Interdepartmental Working Group on Climate Change, $24 \mathrm{pp}$

Global Framework for Climate Services (2011) Climate Knowledge for Action: a global framework for climate services - empowering the most vulnerable, WMO Report 1065, $248 \mathrm{pp}$

Hawkins E, Sutton R (2009) The potential to narrow uncertainty in regional climate predictions. Bull Amer Meteor Soc 90:1095-1107

Hope C (2009) The costs and benefits of adaptation. Assessing the Costs of Adaptation to Climate Change: A Review of the UNFCCC and Other Recent Estimates, International Institute for Environment and Development and Grantham Institute for Climate Change, 100-111

Hourdin F, Foujols M-A, Codron F, Guemas V, Dufresne J-L, Bony S, Denvil S, Guez L, Lott F, Ghattas J, Braconnot P, Marti O, Meurdesoif Y, Bopp L (2013) Impact of the LMDZ atmospheric grid configuration on the climate and sensitivity of the IPSL-CM5A coupled model. Clim Dyn 40:2167-2192

IPCC (2007) Climate Change 2007: Impacts, Adaptation and Vulnerability. In: Party ML, Canziani OF, Palutikof JP, van der Linden PJ, Hanson CE (eds) Contribution of Working Group II to the Fourth Assessment Report of the Intergovernmental Panel on Climate Change. Cambridge University Press, Cambridge, p 976

IPCC-TGCIA (1999) Guidelines on the Use of Scenario Data for Climate Impact and Adaptation Assessment. Version 1. Carter, T.R., M. Hulme, and M. Lal, Intergovernmental Panel on Climate Change, Task Group on Scenarios for Climate Impact Assessment, 69pp. Available at http:/www.ipcc-data.org/guidelines/

Jones C, Giorgi F, Asrar G (2011) The Coordinated Regional Downscaling Experiment: CORDEX An international downscaling link to CMIP5. CLIVAR Exch 16:34-40

Kjellström E, Giorgi F (2010) Introduction to the special issue on "Regional climate model evaluation and weighting". Climate Res 44:117-119

Knutti R, Abramowitz G, Collins M, Eyring V, Gleckler PJ, Hewitson B, Mearns L (2010) Good Practice Guidance Paper on Assessing and Combining Multi Model Climate Projections. In: Stocker TF, Qin D, Plattner G-K, Tignor M, Midgley PM (eds) Meeting Report of the Intergovernmental Panel on Climate Change Expert Meeting on Assessing and Combining Multi Model Climate Projections. IPCC Working Group I Technical Support Unit, University of Bern, Bern, p 13

Lémond J, Dandin P, Planton S, Vautard R, Pagé C, Déqué M, Franchistéguy L, Geindre S, Kerdoncuff M, Li L, Moisselin JM, Noel T, Tourre YM (2011) DRIAS - A step toward French Climate Services. Adv Sci Res 6:179-186

Maraun D, Wetterhall F, Ireson AM, Chandler RE, Kendon EJ, Widmann M, Brienen S, Rust HW, Sauter T, Themeß1 M, Venema VKC, Chun KP, Goodess CM, Jones RG, Onof C, Vrac M, Thiele I (2010) Precipitation downscaling under climate change: Recent developments to bridge the gap between dynamical models and the end user. Rev Geophys 48, RG3003

Mastrandrea, M.D., C.B. Field, T.F. Stocker, O. Edenhofer, K.L. Ebi, D.J. Frame, H. Held, E. Kriegler, K.J. Mach, P.R. Matschoss, G.-K. Plattner, G.W. Yohe, and F.W. Zwiers (2010) Guidance Note for Lead Authors of the IPCC Fifth Assessment Report on Consistent Treatment of Uncertainties. Intergovernmental Panel on Climate Change (IPCC)

Mearns L.O., Giorgi F., Whetton P., Pabon D., Hulme M. and Lal M. (2003) Guidelines for use of climate scenarios developed from Regional Climate Model experiments. Data Distribution Centre of the Intergovernmental Panel of Climate Change, $38 \mathrm{pp}$

Meehl GA, Boer GJ, Covey C, Latif M, Stouffer RJ (2000) The Coupled Model Intercomparison Project (CMIP). Bull Amer Meteor Soc 81:313-318

Moss, R. H. and S.H. Schneider. (2000) Uncertainties in the IPCC TAR: Recommendations to Lead Authors for more consistent assessment and reporting. IPCC Supporting material, guidance papers on the cross cutting issues of the third assessment report of the IPCC. Pachauri, R., Taniguchi, T., and Tanaka, K. (eds.), 33-51.

Palmer, W. C. (1965) Meteorological Drought. Research Paper No. 45, U.S. Department of Commerce Weather Bureau, Washington, D.C

Panofsky H.A. and G.W. Brier (1968) Some Application of Statistics to Meteorology. Pennsylvania State University, $224 \mathrm{pp}$

Patt AG, Schrag D (2003) Using specific language to describe risk and probability. Climatic Change 61:17-30

Taylor KE, Stouffer RJ, Meehl GA (2012) An overview of CMIP5 and the experiment design. Bull Amer Meteor Soc 93(4):485-498

UNECE (2009) Guidance on Water and Adaptation to Climate Change. Convention on the Protection and Use of Transboundary Watercourses and International Lakes, United Nations Publication, 127 pp 
Wright EL, Erickson JD (2003) Climate variability, economic adaptation and investment timing. Int J Global Environ Issues 3:357-368

Yang W, Bárdossy A, Caspary H-J (2010) Downscaling daily precipitation time series using a combined circulation- and regression-based approach. Theor and Appl Climatol 102:439-454 